\title{
Goniothalamin induces mitochondria-mediated apoptosis associated with endoplasmic reticulum stress-induced activation of JNK in HeLa cells
}

\author{
THANET SOPHONNITHIPRASERT ${ }^{1}$, WILAWAN MAHABUSARAKAM ${ }^{2}$, \\ YUKIO NAKAMURA $^{3}$ and RAMIDA WATANAPOKASIN ${ }^{1}$ \\ ${ }^{1}$ Department of Biochemistry, Faculty of Medicine, Srinkharinwirot University, Bangkok 10110; ${ }^{2}$ Department of Chemistry, \\ Faculty of Science, Prince of Songkla University, Hat Yai, Songkhla 90112, Thailand; ${ }^{3}$ Department of Orthopaedic Surgery, \\ Shinshu University School of Medicine, Matsumoto, Nagano 390-8621, Japan
}

Received July 3, 2015; Accepted October 24, 2016

DOI: $10.3892 / \mathrm{ol} .2016 .5381$

\begin{abstract}
Goniothalamin, a natural occurring styryl-lactone isolated from Goniothalamus macrophyllus (Blume) Hook. f. \& Thomson var. macrophyllus, can trigger cancer cell death in various types of cancer cell. The present study focused on elucidation of the mitochondria-mediated apoptosis associated with endoplasmic reticulum (ER) stress-induced activation of c-Jun $\mathrm{NH}_{2}$-terminal kinase (JNK) by goniothalamin in HeLa cervical cancer cells. Cell viability was determined using an MTT assay, and DNA condensation and loss of mitochondrial membrane potential were determined using Hoechst 33342 and JC-1 staining, respectively. Flow cytometry was used for cell cycle and phosphatidyl-serine exposure analyses. Apoptotic-associated ER stress signaling pathways were determined using immunoblotting, reverse transcription-polymerase chain reaction (RT-PCR) and RT-quantitative PCR analyses. The results suggested that goniothalamin suppressed cell proliferation in a time- and dose-dependent manner. The induction of apoptosis was confirmed by increased DNA condensation, loss of mitochondrial membrane potential and cell surface phosphatidyl-serine presentation. The cell cycle analysis demonstrated that the goniothalamin-treated HeLa cells were in G2/M arrest. Determination of the caspase cascade and apoptotic proteins indicated the induction of apoptosis through the intrinsic pathway. In addition, the levels of phosphorylated JNK and the transcription factor, $\mathrm{C} / \mathrm{EBP}$ homologous protein (CHOP), an ER stress-associated apoptotic molecule, were increased
\end{abstract}

Correspondence to: Professor Ramida Watanapokasin, Department of Biochemistry, Faculty of Medicine, Srinakharinwirot University, Sukhumvit 23, Wattana, Bangkok 10110, Thailand E-mail: ramidawa@yahoo.com

Key words: goniothalamin, endoplasmic reticulum stress, c-Jun $\mathrm{NH}_{2}$-terminal kinase, transcription factor $\mathrm{C} / \mathrm{EBP}$ homologous protein, apoptosis, cervical cancer in the goniothalamin-treated cells. These data indicated that goniothalamin exerted a cytotoxic effect against HeLa cells via the induction of mitochondria-mediated apoptosis, associated with ER stress-induced activation of JNK.

\section{Introduction}

The use of natural compounds for treatment is one of the strategies used for cancer therapy and prevention. Styryl-lactone compounds are one type of bioactive compound showing cytotoxic activity towards several cancer cell lines $(1,2)$. These secondary metabolites are found ubiquitously in the Goniothalamus plant genus, indigenous to South East Asia. Goniothalamin is a major styryl-lactone compound extracted from Goniothalamus macrophyllus (Blume) Hook.f. \& Thomson (3). The cytotoxicity of styryl-lactones towards cancer cells is specific, as these compounds have been reported to have no significant effects on normal cell lines, including liver, kidney and fibroblast cell lines (4). Previous studies have shown that goniothalamin induces apoptosis predominantly through the intrinsic pathway. However, the detailed mechanism remains to be fully elucidated (5-11).

Endoplasmic reticulum (ER) stress is stress in the ER caused by the accumulation of unfolded/misfolded proteins. It triggers a response to restore homeostasis in the ER, termed the unfolded protein response (UPR). In mild ER stress, the UPR triggers and promotes ER-associated protein degradation to remove misfolded proteins and then restores normal ER function. In prolonged or severe ER stress, the UPR triggers the cell to commit suicide, usually in the form of apoptosis, also termed ER stress-induced apoptosis. It stimulates the apoptotic-associated signaling of ER stress sensor transmembrane proteins, including protein kinase RNA-like ER kinase (PERK), activating transcription factor 6 (ATF6) and inositol-requiring enzyme $1 \alpha$ (IRE1 $\alpha$ ), and increases the expression of $\mathrm{C} / \mathrm{EBP}$ homologous protein (CHOP), a critical molecule of ER stress-induced apoptosis $(12,13)$.

Apoptosis is acrucialmechanism of anticancerdrug-induced cell death. The majority of chemotherapeutic agents inhibit tumors by triggering cancer cell apoptosis. Apoptosis can be 
activated either by cell surface death receptor- or mitochondria-mediated apoptosis signaling pathways $(14,15)$. However, ER stress is primarily associated with mitochondria-mediated apoptosis. In a number of studies on ER stress, several signaling mechanisms of crosstalk between ER stress and mitochondria-mediated apoptosis have been suggested. These include IRE1 $\alpha \rightarrow$ tumor necrosis factor receptor-associated factor $2 \rightarrow$ apoptosis signal-regulating kinase $1 \rightarrow$ c-Jun $\mathrm{NH}_{2}$-terminal kinase (JNK) and PERK $\rightarrow$ eukaryotic initiation factor $2 \alpha \rightarrow \mathrm{ATF} 4 \rightarrow \mathrm{CHOP}$, and result in the induction of mitochondria-mediated apoptosis $(12,13,16)$. The activation of IRE1 $\alpha$ also activates the endonuclease domain, which splices mRNA of X-box binding protein 1 (XBP1) and results in expression of the spliced form of the UPR gene $(12,13)$. In addition, the activation of IRE1 $\alpha$ leads to the phosphorylation of JNK, which is one of three major mitogen-activated protein kinase (MAPK) pathways that have generally been associated with pro-apoptotic action in several cell types (16-18). Thus, this information indicates that JNK activation is sustained in severe ER stress-induced apoptotic cell death.

Cervical cancer is the fourth most common type of cancer among women and the seventh most common worldwide $(19,20)$. Annual incidence rates of $>450,000$ and $>240,000$ cases have been estimated in low- and middle-income countries, respectively, with the mortality rates in these countries estimated to reach $>88 \%$ and predicted to increase to at least $91.5 \%$ by 2030 (21). This emphasizes the requirement for identifying effective and non-cytotoxic chemical agents for chemoprevention and treatment. The HeLa cell line is most widely used as a cervical cancer model for investigating human cellular and molecular biology (22). The present study investigated the induction of mitochondria-mediated apoptosis associated with the ER stress-induced activation of JNK caused by goniothalamin treatment in HeLa cells. As the first investigation of the effects of goniothalamin on ER stress-induced activation of JNK-associated apoptosis on cancer cells, the results may be useful for enabling further investigations of the drug action of styryl-lactone compounds and indicate the potential application of goniothalamin as an anticancer agent for the treatment of cervical cancer.

\section{Materials and methods}

Chemicals and antibodies. Goniothalamin was obtained from Professor Wilawan Mahabusarakam of the Faculty of Science, Prince of Songkla University (Songkhla, Thailand) in purified powder form, the structure of which is shown in Fig. 1A. The stems of Goniothalamus macrophyllus were collected from Songkhla province in the southern region of Thailand in September 2007. Identification was performed by Mr. Ponlawat Pattarakulpisutti of the Department of Biology, Faculty of Science, Prince of Songkla University. The specimen (Uraiwan 01) was deposited in the Herbarium of the Department of Biology, Faculty of Science, Prince of Songkla University. Antibodies (Abs) for immunoblotting analysis, including mouse monoclonal Abs against $\mathrm{CHOP}$, and rabbit monoclonal Abs against glucose-regulated protein 78 (GRP78), poly ADP ribose polymerase (PARP), caspase-3, caspase-9, p38, phosphorylated (phospho)-p38 at Thr180/Tyr182, stress-activated protein kinase (SAPK)/JNK,
phospho-SAPK/JNK at Thr183/Tyr185, p44/42 MAPK [extracellular signal-regulated kinase (Erk1/2)], phospho-p44/42 MAPK (Erk1/2) at Thr202/Tyr204, p53, B cell lymphoma 2 (Bcl2), phospho-Bcl2 at Ser70, Bcl2-associated X protein (Bax), Bcl2-associated death promoter (Bad) and $\beta$-actin, and anti-mouse immunoglobulin $\mathrm{G}$ and anti-rabbit immunoglobulin $\mathrm{G}$ horseradish peroxidase-conjugated secondary antibodies were obtained from Cell Signaling Technology, Inc. (Danvers, MA, USA).

Cell culture. The HeLa human cervical cancer cell line was obtained from the American Type Culture Collection (Manassas, VA). The cells were maintained in Dulbecco's modified Eagle's medium (DMEM; Gibco Life Technologies; Thermo Fisher Scientific, Inc., Waltham, MA, USA) supplemented with $10 \%$ fetal bovine serum (GE Healthcare Life Sciences, Little Chalfont, UK), $100 \mathrm{U} / \mathrm{ml}$ penicillin and $100 \mu \mathrm{g} / \mathrm{ml}$ streptomycin (GE Healthcare Life Sciences) at $37^{\circ} \mathrm{C}$ in a humidified $5 \% \mathrm{CO}_{2}$ atmosphere, and were used for assays during the exponential phase of growth.

Cell viability assessment using an MTT assay. The cells were plated at a density of $5 \times 10^{3}$ cells/well in 96 -well plates and allowed to grow for $24 \mathrm{~h}$. The cells were then treated with goniothalamin at serial concentrations of 100, 50, 25, $12.5,6.25,3.125$ and $1.562 \mu \mathrm{M}$, and the control group was treated with $0.5 \%$ DMSO. The cytotoxicity of goniothalamin was determined by cell proliferation analysis using an MTT assay, as described by Denizot and Lang (23). Briefly, the cells were incubated at $37^{\circ} \mathrm{C}$ with the indicated concentration of goniothalamin for $24 \mathrm{~h}$ to determine the half maximal inhibitory concentration $\left(\mathrm{IC}_{50}\right)$ value, or at different time points $(3$, 6,9 and $12 \mathrm{~h}$ ), to investigate the effect of time and dose on cell viability. Following the indicated treatment, $0.5 \mathrm{mg} / \mathrm{ml}$ of MTT solution (Sigma-Aldrich; Merck Millipore, Darmstadt, Germany) dissolved in culture medium was added and the cells were incubated for $2 \mathrm{~h}$ at $37^{\circ} \mathrm{C}$ with $5 \% \mathrm{CO}_{2}$. The MTT solution was then aspirated and $100 \mu \mathrm{l}$ of DMSO was added to each well to dissolve the formazan crystals, a product of cell respiration reacting with MTT tetrazolium compound to indicate viable cells. The absorbance at $540 \mathrm{~nm}$ was quantified using an Epoch ${ }^{\mathrm{TM}}$ microplate spectrophotometer and analyzed using Gen5 ${ }^{\text {TM }}$ data analysis software (BioTek Instruments, Inc., Winooski, VT, USA).

Hoechst 33342 staining analysis for chromatin condensation. The fluorescent dye, Hoechst 33342, was used to detect chromatin condensation, which is a characteristic of apoptotic cells. The protocol was modified from Oberhammer et al (24). The HeLa cells were plated at a density of $2 \times 10^{5}$ cells/well in 6 -well plates and treated with $15 \mu \mathrm{M}$ of goniothalamin for $0,3,6,9$ and $12 \mathrm{~h}$ at $37^{\circ} \mathrm{C}$ with $5 \%$ $\mathrm{CO}_{2}$. The treated cells were then washed with PBS and fixed with $4 \%$ paraformaldehyde for $15 \mathrm{~min}$ at room temperature. The fixed cells were washed with PBS and stained with $5 \mu \mathrm{g} /$ $\mathrm{ml}$ of Hoechst 33342 solution (Invitrogen ${ }^{\mathrm{TM}}$; Thermo Fisher Scientific, Inc.) for $15 \mathrm{~min}$. The cells were washed with PBS and the plates were observed using a fluorescence microscope (IX73; Olympus Corporation, Tokyo, Japan) using U-MWU2 mirror units for ultraviolet excitation. 
Cell cycle determination. The HeLa cells were plated at a density of $2 \times 10^{5}$ cells/well in 6 -well plates. The cells were incubated with $15 \mu \mathrm{M}$ of goniothalamin for various durations of $0,3,6,9$ and $12 \mathrm{~h}$ at $37^{\circ} \mathrm{C}$ with $5 \% \mathrm{CO}_{2}$. The protocol used for the flow cytometric analysis of cell cycle distributions using propidium iodide was modified from Krishan (25). Following treatment, the whole cells were collected and fixed with ethanol (70\% final concentration). The fixed cells were washed with PBS and stained with $50 \mu \mathrm{g} / \mathrm{ml}$ propidium iodide solution (Invitrogen ${ }^{\mathrm{TM}}$; Thermo Fisher Scientific, Inc.). The stained cells were incubated at $4^{\circ} \mathrm{C}$ in the dark, and were then sorted and analyzed for DNA content using the CyAn ${ }^{\mathrm{TM}}$ ADP Beckman Coulter International S.A. Flow cytometer and Kaluza $^{\circledR}$ flow analysis software (Beckman Coulter, Inc., Brea, CA, USA), respectively.

Cell surface phosphatidyl-serine determination. The HeLa cells were plated at a density of $2 \times 10^{5}$ cells/well in 6 -well plates. The cells were incubated with $15 \mu \mathrm{M}$ goniothalamin for $0,3,6,9$ and $12 \mathrm{~h}$ at $37^{\circ} \mathrm{C}, 5 \% \mathrm{CO}_{2}$. DMSO-treated HeLa cells at a $0.5 \%$ final concentration were used as a control. The whole cells were collected and stained according to the manufacturer's protocol of the fluorescein isothiocyanate (FITC) Annexin V/Dead Cell apoptosis kit for flow cytometry (Invitrogen $^{\mathrm{TM}}$; Thermo Fisher Scientific, Inc.). Following staining, the stained cells were sorted and analyzed for outer membrane phosphatidylserine content using the CyAn ${ }^{\mathrm{TM}}$ ADP Beckman Coulter International S.A. flow cytometer and Kaluza ${ }^{\circledR}$ flow analysis software (Beckman Coulter, Inc.), respectively.

Analysis of the loss of mitochondrial membrane potential. The loss of mitochondrial membrane potential was detected using JC-1 dye. The protocol for the observation of mitochondrial membrane potential under a fluorescence microscope using JC-1 dye was modified from Perelman et al (26). The HeLa cells were treated with $15 \mu \mathrm{M}$ goniothalamin for 3 and $6 \mathrm{~h}$, and DMSO-treated HeLa cells at a final concentration of $0.5 \%$ were used as a control. The treated cells were stained with $10 \mu \mathrm{g} / \mathrm{ml} \mathrm{JC}-1$ (Invitrogen ${ }^{\mathrm{TM}}$; Thermo Fisher Scientific, Inc.) and washed with PBS to remove excess dye. Subsequently, the stained cells were qualitatively analyzed by observation under a fluorescence microscope (IX73; Olympus Corporation) with U-MWB2 mirror units for excitation at $480 \mathrm{~nm}$. The aggregated form is emitted at red light $(590 \mathrm{~nm})$, indicating healthy mitochondria, whereas monomer formation is emitted at green light $(525 \mathrm{~nm})$, indicating damaged mitochondria or loss of mitochondrial membrane potential.

Analysis of $m R N A$ levels of spliced XBP1 using reverse transcription-polymerase chain reaction $(R T-P C R)$ analysis. The HeLa cells were plated at a density of $5 \times 10^{4}$ cells/well in 12 -well plates. The cells were incubated with $15 \mu \mathrm{M}$ goniothalamin for $0,3,6,9$ and $12 \mathrm{~h}$ at $37^{\circ} \mathrm{C}, 5 \% \mathrm{CO}_{2}$. DMSO-treated HeLa cells at a final concentration of $0.5 \%$ were used as a control. The whole cells were collected and their RNA was extracted using QIAzol ${ }^{\mathrm{TM}}$ lysis reagent (Qiagen N.V., Venlo, The Netherlands) and cDNA was synthesized by RT using a RevertAid $^{\mathrm{TM}}$ First Strand cDNA Synthesis kit (Fermentas ${ }^{\mathrm{TM}}$; Thermo Fisher Scientific, Inc.) with $2 \mu \mathrm{g}$ of total RNA from each sample. These steps were performed according to the manufacturer's protocol. The PCR step was performed using Taq polymerase (Vivantis Technologies Sdn. Bhd., Selangor Darul Ehsan, Malaysia) using a pair of primers corresponding to the spliced site of the XBP1 gene; forward 5'-AATGAAGTG AGGCCAGTGGCC-3' and reverse 5'-AATACCGCCAGA ATCCATGGG-3'. In detail, the PCR step was performed in a $20 \mu \mathrm{l}$ reaction volume using $1 \mu \mathrm{l}$ of cDNA with a PCR mixture containing $0.3 \mu \mathrm{M}$ forward primer, $0.3 \mu \mathrm{M}$ reverse primer, $0.25 \mathrm{mM}$ deoxynucleotide triphosphate, $10 \mathrm{mM}$ Tris- $\mathrm{HCl}$, $50 \mathrm{mM} \mathrm{KCl}, 0.01 \%$ Triton X-100, $1.5 \mathrm{mM} \mathrm{MgCl}_{2}$ and 2 units of Taq polymerase. The PCR thermal cycler conditions used were as follows: $94^{\circ} \mathrm{C}$ for $2 \mathrm{~min}$, followed by 35 cycles at $94^{\circ} \mathrm{C}$ for $15 \mathrm{sec}, 55^{\circ} \mathrm{C}$ for $30 \mathrm{sec}$ and $72^{\circ} \mathrm{C}$ for $30 \mathrm{sec}$; final extension was not included. The PCR products were analyzed using $8 \%$ polyacrylamide gel electrophoresis with ethidium bromide staining. The unspliced- and spliced- forms of the XBP1 gene were indicated at 125 and 99 base pairs, respectively.

Analysis of ER stress-mediated mRNA expression using $R T$-quantitative PCR (RT-qPCR) analysis. The HeLa cells were plated at a density of $5 \times 10^{4}$ cells/well in 12 -well plates. The cells were incubated with $15 \mu \mathrm{M}$ goniothalamin for $0,3,6$, 9 and $12 \mathrm{~h}$ at $37^{\circ} \mathrm{C}, 5 \% \mathrm{CO}_{2}$. DMSO-treated HeLa cells at a final concentration of $0.5 \%$ were used as a control. The whole cells were collected and the RNA was extracted using QIAzol ${ }^{\mathrm{TM}}$ lysis reagent (Qiagen N.V.). The cDNA was synthesized by RT using the RevertAid ${ }^{\text {TM }}$ First Strand cDNA Synthesis kit (Fermentas $^{\mathrm{TM}}$; Thermo Fisher Scientific, Inc.) with $2 \mu \mathrm{g}$ of total RNA from each sample, and the synthesized cDNA was diluted 20X prior to use in the qPCR step. The subsequent qPCR step was performed in a $10-\mu 1$ reaction volume containing $1 \mu \mathrm{l}$ diluted cDNA, SYBR ${ }^{\circledR}$ Select Master Mix (Applied Biosystems; Thermo Fisher Scientific, Inc.), $0.2 \mu \mathrm{M}$ forward primer and $0.2 \mu \mathrm{M}$ reverse primer. The following primers were used for amplification: CHOP, forward 5'-GCG CATGAAGGAGAAAGAAC-3' and reverse 5'-TCACCA TTCGGTCAATCAGA-3'; ER-localized Dna J homologue 4 (ERdj4), forward 5'-AAAATAAGAGCCCGGATGCT-3' and reverse 5'-CGCTTCTTGGATCCAGTGTT-3'; growth arrest and DNA damage protein 34 (GADD34), forward 5'-AAA CCAGCAGTTCCCTTCCT-3' and reverse 5'-CTCTTCCTC GGCTTTCTCCT-3'; GRP78, forward 5'-GCTCGACTCGAA TTCCAAAG-3' and reverse 5'-GATCACCAGAGAGCA CACCA-3'; and GAPDH, forward 5'-AGGTCGGAGTCAACG GATTT-3' and reverse 5'-TAGTTGAGGTCAATGAAGGG-3'. The qPCR cycling conditions were optimized for all the primers and performed according to the SYBR ${ }^{\circledR}$ Select Master Mix user guide's protocol as follows: $50^{\circ} \mathrm{C}$ for $2 \mathrm{~min}, 95^{\circ} \mathrm{C}$ for $2 \mathrm{~min}$, and $40 \mathrm{cycles}$ at $95^{\circ} \mathrm{C}$ for $15 \mathrm{sec}$ and $60^{\circ} \mathrm{C}$ for $60 \mathrm{sec}$. The qPCR amplification was analyzed using the CFX96 Touch $^{\mathrm{TM}}$ Real-Time PCR detection system with CFX Manager ${ }^{\mathrm{TM}}$ software (Bio-Rad Laboratories, Inc., Hercules, CA, USA). The relative quantification $(\Delta \Delta \mathrm{Cq})$ method described by Livak and Schmittgen (27) was used to analyze the results of gene expression using GAPDH as a reference gene. The gene expression calculation was performed according to the CFX Manager ${ }^{\mathrm{TM}}$ software manufacturer's protocol.

Analysis of protein expression via immunoblotting. SDS-PAGE and immunoblotting were used to detect the 
expression levels of apoptotic intermediate proteins. The procedures for SDS-PAGE and immunoblotting were modified from Taylor et al (28). The HeLa cells were plated at a density of $2 \times 10^{5}$ cells/well in 6 -well plates and incubated with $15 \mu \mathrm{M}$ goniothalamin for $0,3,6,9$ and $12 \mathrm{~h}$ at $37^{\circ} \mathrm{C}$ with $5 \%$ $\mathrm{CO}_{2}$ DMSO-treated HeLa cells at a final concentration of $0.5 \%$ were used as a control. The whole cells were then collected for protein extraction in RIPA lysis buffer, containing $50 \mathrm{mM}$ Tris- $\mathrm{HCl}$ (pH 7.4), $1 \%$ NP-40, $0.5 \% \mathrm{C}_{24} \mathrm{H}_{39} \mathrm{NaO}_{4}, 0.1 \%$ SDS, $150 \mathrm{mM} \mathrm{NaCl}, 2 \mathrm{mM}$ EDTA and $50 \mathrm{mM} \mathrm{NaF}$. Protein concentration was determined using Bio-Rad ${ }^{\circledR}$ Protein Assay kit (Bio-Rad Laboratories, Inc.), which is based on the Bradford method(29) using bovine serum albumin as the standard protein. The cell lysates (containing $10 \mu \mathrm{g}$ of protein) were separated on $8-15 \%$ acrylamide gels by SDS-PAGE and then transferred onto polyvinylidene difluoride membranes (Merck Millipore), following which, they were blocked with $5 \%$ skimmed-milk in TBS-Tween buffer for $1 \mathrm{~h}$ at room temperature. The membranes were then incubated with mouse monoclonal Abs against CHOP $(1: 1,000)$, and rabbit monoclonal Abs against GRP78 (1:1,000), PARP $(1: 1,000)$, caspase-3 $(1: 1,000)$, caspase-9 (1:1,000), p38 (1:1,000), phospho-p38 at Thr180/ Tyr182 (1:1,000), SAPK/JNK (1:1,000), phospho-SAPK/JNK at Thr183/Tyr185 (1:1,000), p44/42 MAPK (Erk1/2; 1:1,000), phospho-p44/42 MAPK (Erk1/2) at Thr202/Tyr204 (1:1,000), p53 (1:1,000), Bcl2 (1:1,000), phospho-Bcl2 at Ser70 (1:1,000), Bax $(1: 1,000)$, Bad $(1: 1,000)$ and $\beta$-actin $(1: 5,000)$ overnight at $4^{\circ} \mathrm{C}$. Following incubation with anti-mouse immunoglobulin $\mathrm{G}$ or anti-rabbit immunoglobulin $\mathrm{G}$ horseradish peroxidase-conjugated secondary antibodies $(1: 10,000)$ for $1 \mathrm{~h}$ at room temperature, the signals were developed using Immobilon $^{\mathrm{TM}}$ Western Chemiluminescent HRP substrate (Merck Millipore) and detected using a chemiluminescent imaging system (GeneGnome gel documentation; Synoptics Ltd., Cambridge, UK).

Statistical analysis. To compare the data from different treatment groups, student's $t$-test was used. Microsoft Excel version 2010 software (Microsoft Corporation, Redmond, WA, USA) was used to analyze the data. All data presented were obtained from at least three independent experiments and are presented as the mean \pm standard deviation. $\mathrm{P} \leq 0.05$ was considered to indicate a statistically significant difference.

\section{Results}

Effect of goniothalamin on HeLa cell viability and toxicity. The cytotoxicity of goniothalamin towards HeLa cells was analyzed and the results are shown in Fig. 1B and C. Goniothalamin induced a cytotoxic effect with an $\mathrm{IC}_{50}$ value of $13.28 \pm 2.89 \mu \mathrm{M}$ at $24 \mathrm{~h}$. Goniothalamin induced these cytotoxic effects in a time- and dose-dependent manner.

Effect of goniothalamin on chromatin condensation. An important characteristic of apoptotic cells is chromatin condensation. Goniothalamin was shown to induce chromatin condensation and apoptotic body-like formation in the treated HeLa cells (Fig. 2A). The number of cells with chromatin condensation following treatment with $15 \mu \mathrm{M}$ goniothalamin increased in a time-dependent manner.
Loss of mitochondrial membrane potential. The loss of mitochondrial membrane potential is one of the apoptotic characteristics of the intrinsic pathway. The present study investigated this event using the fluorescent dye, JC-1, to stain the treated HeLa cells. The results showed that goniothalamin increased the presence of green puncta, indicating the monomer form of JC-1 in cells with loss of mitochondrial membrane potential. Red puncta were observed in the control sample, indicating the aggregated form of JC-1 in cells with a normal mitochondrial membrane potential or healthy cells (Fig. 2B). These results indicated that goniothalamin induced the loss of mitochondrial membrane potential in the HeLa cells and this was likely due to the intrinsic apoptotic pathway.

Effect of goniothalamin on the regulation of cell cycle arrest. The majority of apoptosis-inducing compounds interrupt cell cycle regulation, which may lead to cell cycle arrest and subsequent apoptosis. Therefore, the present study investigated the effect of goniothalamin on the cell cycle of HeLa cells treated with $15 \mu \mathrm{M}$ goniothalamin. The results indicated that goniothalamin predominantly affected cell cycle arrest at the G2/M phase in a time-dependent manner (Fig. 3). The increase in $\mathrm{G} 2 / \mathrm{M}$ arrest was $\sim 15 \%$ following treatment with $15 \mu \mathrm{M}$ goniothalamin for $12 \mathrm{~h}$.

Effect of goniothalamin on cell surface phosphatidyl-serine presentation. The translocation of phosphatidyl-serine out of the cell membrane and exposed to annexin $\mathrm{V}$ is an important characteristic in differentiating cell apoptosis from necrosis. In the present study, goniothalamin predominantly induced HeLa cell accumulation at the early apoptotic stage (Fig. 4). The results showed that goniothalamin increased the percentage of total apoptotic HeLa cells to $16.59 \pm 2.4 \%$ within $12 \mathrm{~h}$, indicating the induction of apoptosis.

Effect of goniothalamin on ER stress. The mRNA and protein expression levels of CHOP following treatment with goniothalamin are shown in Fig. 5A and B, respectively, which showed increased mRNA and protein levels of CHOP, the key mediator of ER stress-induced apoptosis. The increased expression of other ER stress-associated genes, including ERdj4 and GADD34, were also detected, with the exception of GRP78. In addition, the results of the XBP1 splicing analysis (Fig. 5C) showed an increase in the level of spliced XBP1 following goniothalamin treatment. These results indicated that goniothalamin triggered ER stress in the HeLa cells.

Induction of apoptosis is associated with the ER stress-induced activation of JNK, which is triggered by goniothalamin. The protein expression levels of apoptotic-associated mediators are shown in Fig. 6, which corresponded with induction of ER stress. The results, as shown in Fig. 6A, revealed that phosphorylation of SAPK/JNK and p38 increased in a time-dependent manner, which was not observed for ERK. The inhibition of $\mathrm{Bcl} 2$ through phosphorylation was also observed. The level of phospho-Bcl2 at Ser70, one of the phosphorylated residues activated by phospho-SAPK/JNK, increased in a time-dependent manner. The activation of p38 and SAPK/ JNK was closely associated with the inhibition of $\mathrm{Bcl} 2$ via phosphorylation, leading to apoptosis (Fig. 6C). This event led 
A<smiles>O=C1C=CCC(/C=C/c2ccccc2)O1</smiles>

B

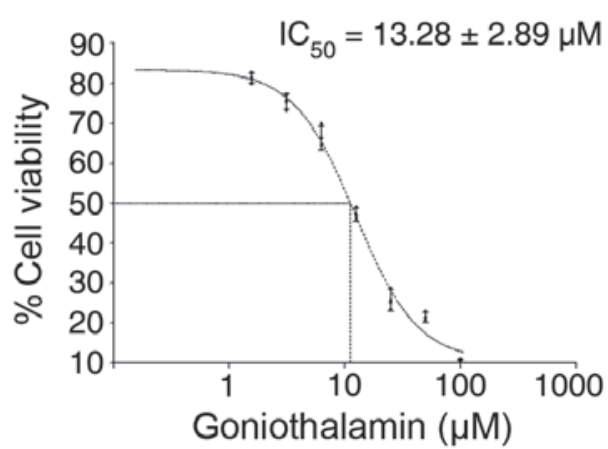

C

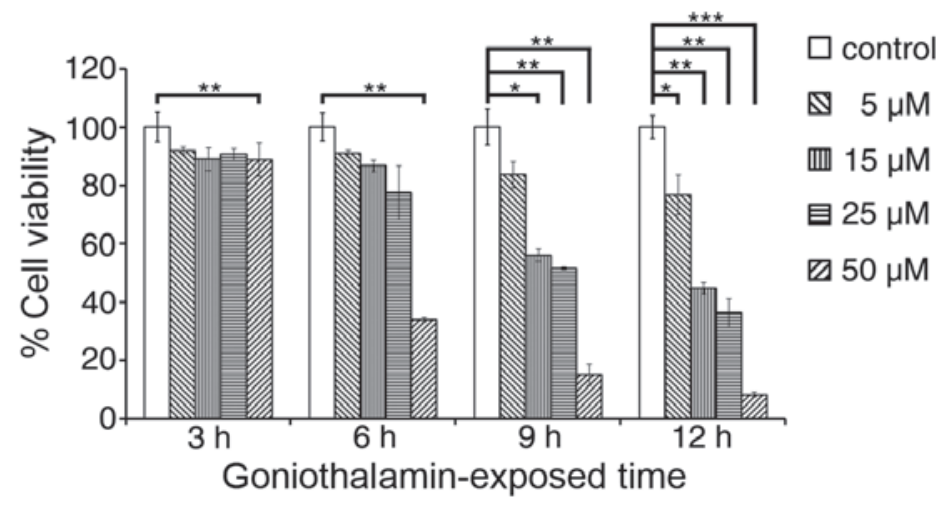

Figure 1. Effect of goniothalamin on cell viability of HeLa cells. (A) Structure of goniothalamin. (B) Evaluation of the IC $\mathrm{C}_{50}$ using an MTT assay. (C) Effects of goniothalamin on cell viability at various concentrations and exposure durations. Values are expressed as the mean \pm standard deviation from at least three independent experiments. ${ }^{*} \mathrm{P}<0.05,{ }^{* *} \mathrm{P}<0.01$ and ${ }^{* * *} \mathrm{P}<0.001$, vs. control for each exposure. $\mathrm{IC}_{50}$, half maximal inhibitory concentration.

A

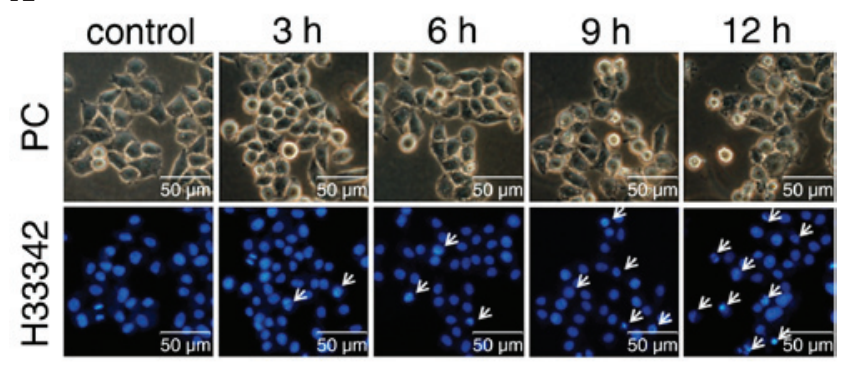

B
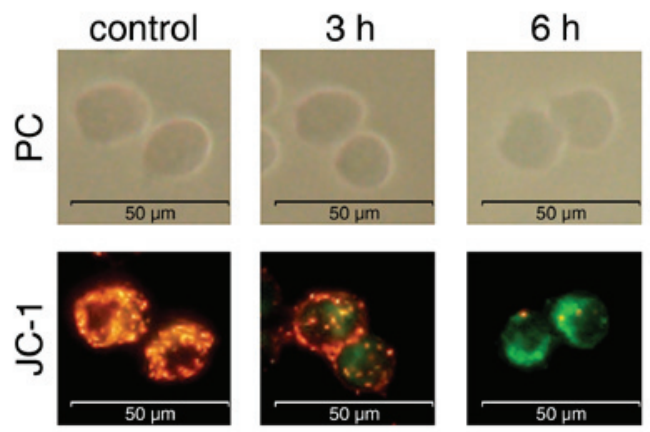

Figure 2. Induction of apoptosis in HeLa cells by goniothalamin. (A) Chromatin condensation was shown using Hoechst 33342 staining. Cells were treated with $15 \mu \mathrm{M}$ goniothalamin for 3, 6, 9 and $12 \mathrm{~h}$. Chromatin condensation is indicated by white arrows. (B) Mitochondrial membrane potential was shown using JC-1 staining. Cells were treated with $15 \mu \mathrm{M}$ of goniothalamin for 3 and $6 \mathrm{~h}$. Red puncta altered to green indicating loss of mitochondrial membrane potential, a characteristic of the mitochondrial mediated apoptotic pathway in early apoptosis. PC, phase-contrast; H33342, Hoechst 33342. to mitochondrial dysfunction and the induction of apoptosis via the intrinsic pathway. Activation of the caspase cascade components (Fig. 6B), including the initiator caspase-9, executioner caspase-3 and PARP, were detected upon treatment with $15 \mu \mathrm{M}$ goniothalamin, indicating the induction of apoptosis. These results suggested that goniothalamin induced mitochondria-mediated apoptosis, which was associated with ER stress-induced activation of the JNK pathway.

\section{Discussion}

At present, the use of traditional medicine or natural compounds extracted from plants is of interest as it may reduce the adverse effects of conventional therapies (30). Previous studies have reported that goniothalamin inhibits proliferation and induces apoptosis in various cancer cell lines, including human cervical cancer (7-11). Although the effect of goniothalamin on the induction of apoptosis in the HeLa cell line was reported previously by Alabsi et al $(9,10)$, the molecular signaling pathway of goniothalamin-induced apoptosis in HeLa cells remains to be elucidated. The present study is the first, to the best of our knowledge, to indicate that ER stress-induced activation of JNK was associated with goniothalamin-induced HeLa cervical cancer cell apoptosis. The results showed that goniothalamin reduced HeLa cell viability with an $\mathrm{IC}_{50}$ value of $13.28 \pm 2.89 \mu \mathrm{M}$, and this reduced viability occurred in a dose- and time-dependent manner. In addition, the induction of apoptosis by goniothalamin was assessed by examining chromatin condensation, cell cycle arrest, cell surface phosphatidyl-serine presentation and caspase cascade 


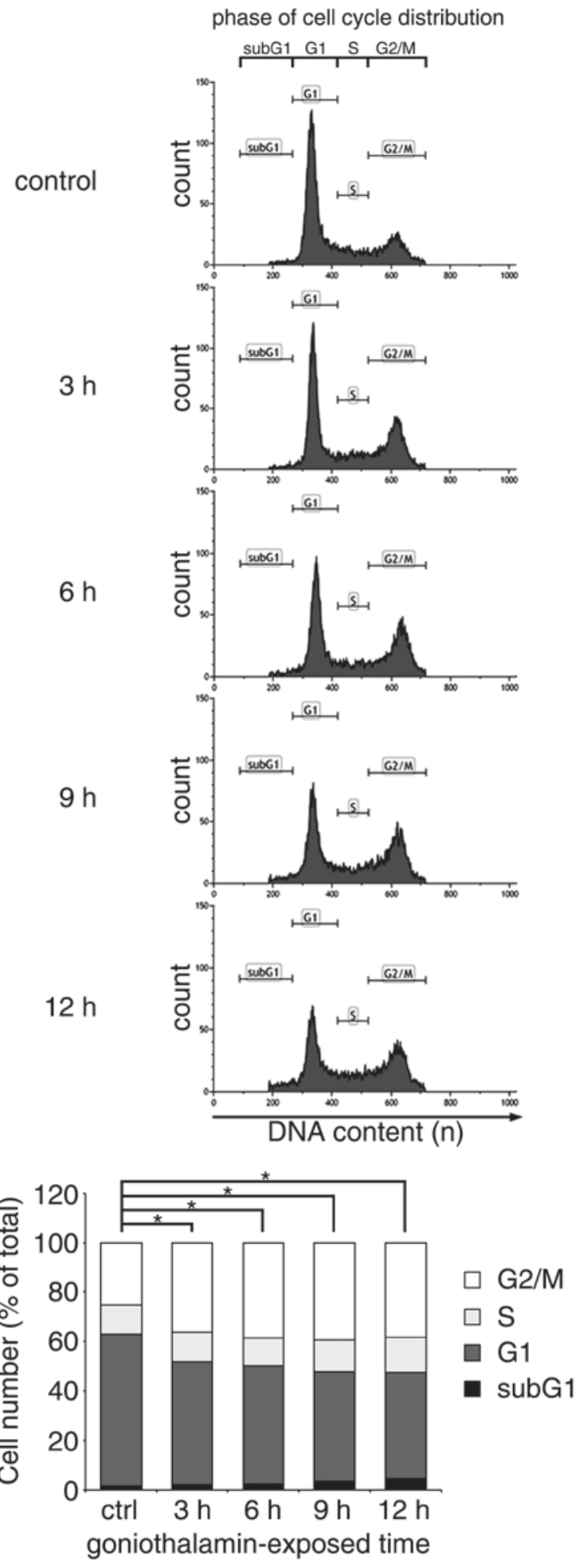

Figure 3. Induction of cell cycle arrest in HeLa cells by goniothalamin. Distribution of the cell cycle phases in HeLa cells treated with $15 \mu \mathrm{M}$ of goniothalamin for 3,6,9 and $12 \mathrm{~h}$, as analyzed using flow cytometry following staining with propidium iodide. The results showed that goniothalamin triggered cell cycle accumulation predominantly in the G2/M phase. Data are presented as the mean of each cell cycle phase. All data were obtained from at least three independent experiments, and the mean values of $\mathrm{G} 2 / \mathrm{M}$ arrest for individual exposure durations were compared with the control. ${ }^{*} \mathrm{P}<0.05$, vs. ctrl (control). n, number of sets of chromosomes in a cell or ploidy.

activation in goniothalamin-treated HeLa cells. The effect of goniothalamin on cell cycle distribution was investigated by observing DNA content in the treated cells using propidium
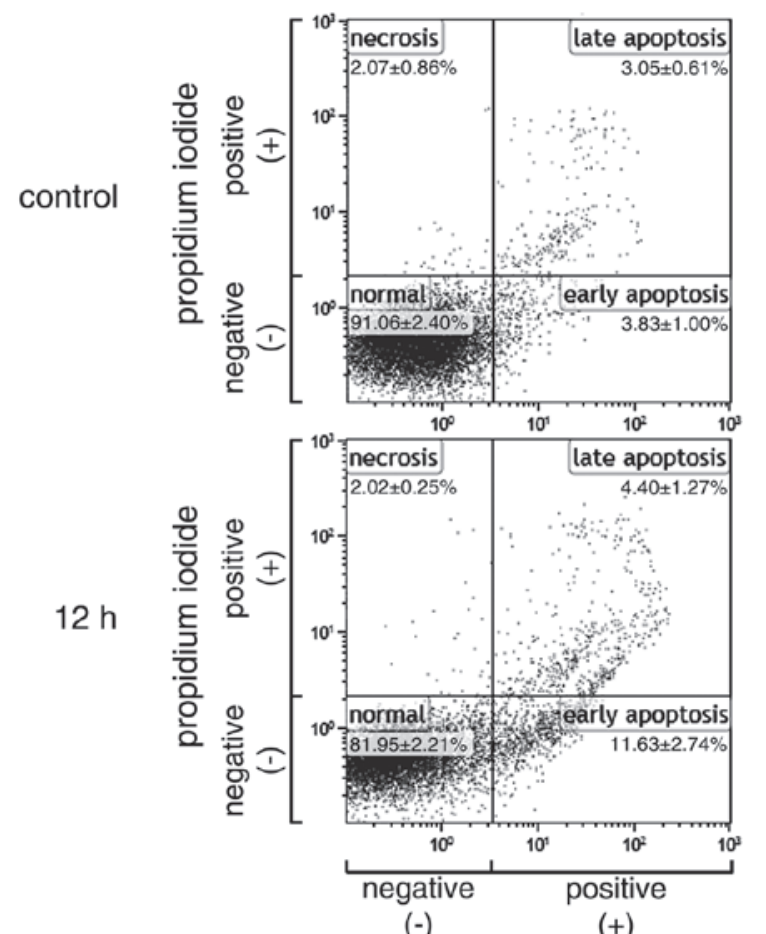

Annexin V-FITC

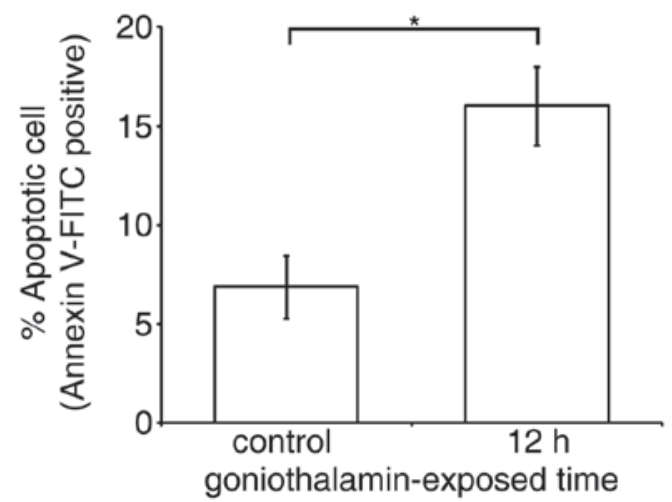

Figure 4. Increases of cell surface phosphatidyl-serine presentation in HeLa cells by goniothalamin. The Cell surface presentation of phosphatidyl-serine presentation on HeLa cells treated with $15 \mu \mathrm{M}$ goniothalamin for $12 \mathrm{~h}$ was detected via Annexin $\mathrm{V}$ assessment. The percentage in each quadrant indicates the levels of normal cells (annexin V-FITC-/propidium iodide-), early apoptotic cells (annexin $\mathrm{V}^{-\mathrm{FITC}^{+}}$/propidium iodide), late apoptotic cells (annexin $\mathrm{V}-\mathrm{FITC}^{+} /$propidium iodide ${ }^{+}$) and necrotic cells (annexin V-FITC-propidium iodide ${ }^{+}$). These results indicated that goniothalamin induced phosphatidyl-serine exposure, indicative of apoptosis induction. The results shown are representative data from three independent experiments. Percentages of apoptotic cells are presented as the mean \pm standard deviation from at least three independent experiments. ${ }^{*} \mathrm{P}<0.05$, vs. control. FITC, fluorescein isothiocyanate.

iodide staining. The results showed that goniothalamin caused accumulation at the G2/M phase of arrest in apoptosis (Fig. 3). This response differed from the cell cycle arrest induced by goniothalamin in Ca9-22 oral cancer cells and HL-60 promyelocytic leukemia cells, which showed subG1 arrest $(11,31)$. However, cell cycle arrest in MDA-MB-231 breast cancer cells showed accumulation at the G2/M phase of arrest (32). This suggested that differences in cell cycle arrest depend on the type of cancer cell. In addition, the accumulation of cells at the G2/M phase arrest can trigger p53-dependent p38 
A
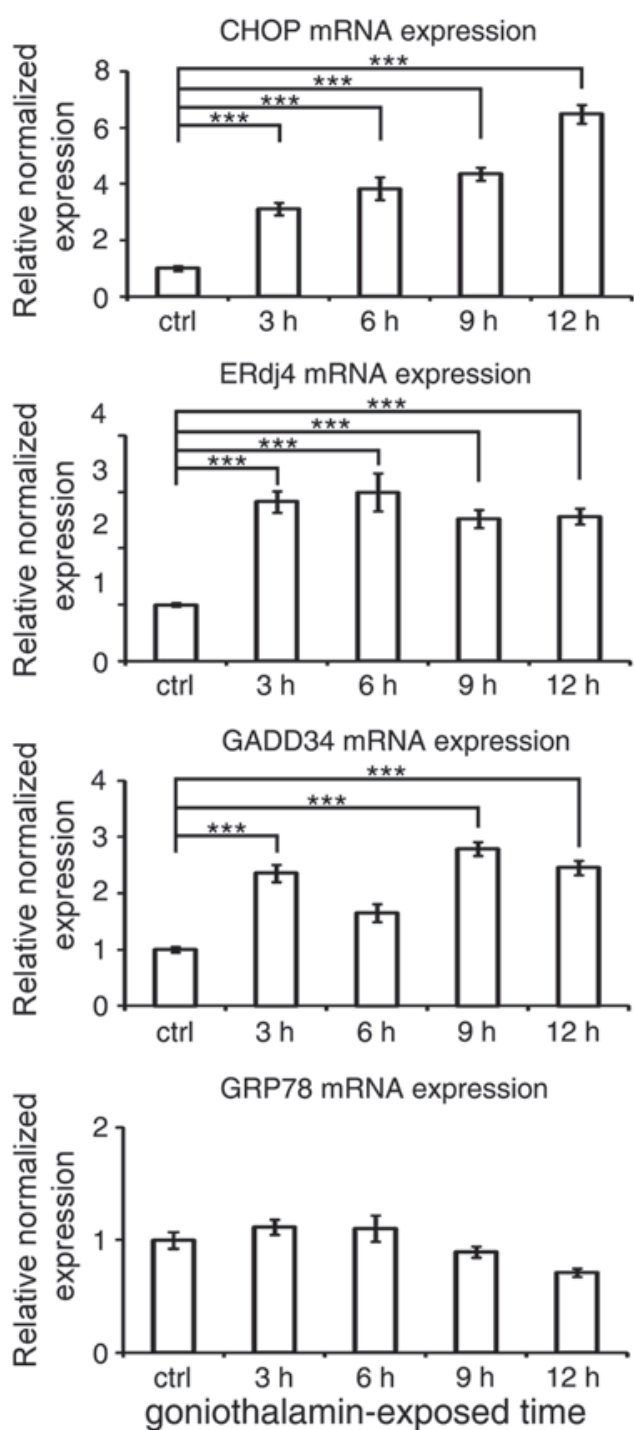

B

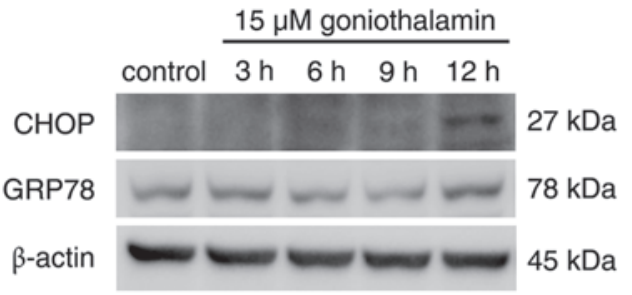

C

$15 \mu \mathrm{M}$ goniothalamin
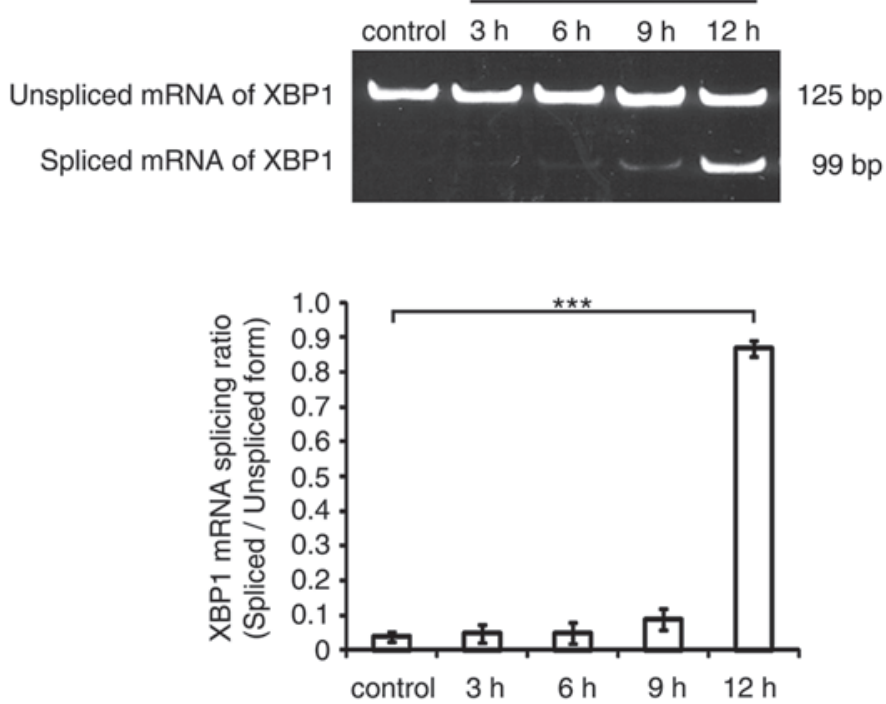

Figure 5. ER stress is triggered in goniothalamin-treated HeLa cells. (A) mRNA expression levels of ER stress-associatead genes, including CHOP, ERdj4, GADD34 and GRP78 in HeLa cells treated with $15 \mu \mathrm{M}$ of goniothalamin for 3, 6, 9 and $12 \mathrm{~h}$ using RT-qPCR analysis. (B) Immunoblotting analysis of ER stress mediators, CHOP and GRP78. Images shown are representative from three independent experiments. (C) Analysis of the splicing of XBP1 mRNA using RT-PCR analysis. Values of fluorescence intensity are presented as the mean \pm standard deviation from at least three independent experiments. ${ }^{* * * *} \mathrm{P}<0.001$, vs. ctrl (control). ER, endoplasmic reticulum; CHOP, C/EBP homologous protein; ERdj4, ER-localized Dna J homologue 4; GADD34, growth arrest and DNA damage protein 34; GRP78; glucose-regulated protein 78; RT-qPCR, reverse transcription-quantitative polymerase chain reaction; ctrl, control.

MAPK activation (33), and the goniothalamin-induced G2/M phase arrest was associated with p38 MAPK phosphorylation and increased expression of p53 (Fig. 6A and C). In early apoptosis, phosphatidyl-serine is translocated from the inner surface to the outer surface of the cellular membrane due to the loss of membrane asymmetry, which can be detected by Annexin V (34-37). In the present study, it was observed that the numbers of positively-stained Annexin V cells were increased in the goniothalamin-treated HeLa cells, compared with the control (Fig. 4). This effect of goniothalamin on the HeLa cells correlated with previous reports, which showed goniothalamin-induced increases in positively-stained Annexin V cells in cell lines, including human leukemia cells, hepatoblastoma and urinary bladder cancer cells $(5,11,38,39)$. These results also confirmed the ability of goniothalamin to induce apoptosis.
During apoptosis, the loss of mitochondrial membrane potential is a characteristic of early apoptosis, which triggers the mitochondria-mediated pathway. In this process, following mitochondrial membrane collapse, the mitochondrial permeability transition pore (MPTP) is opened by pro-apoptotic signaling proteins, including Bax and Bid, resulting in decreased mitochondrial membrane potential, following which cytochrome $c$ is released into the cytoplasm and induces activation of the apoptosome-dependent apoptosis cascade (40). In the present study, the loss of mitochondrial membrane potential was detected by staining cells with specific fluorescent dye, JC-1, which can selectively enter mitochondria through the MPTP and alters in color from red to green as the membrane potential decreases. The results of the present study indicated that goniothalamin induced the loss of mitochondrial membrane potential in HeLa cells 
A

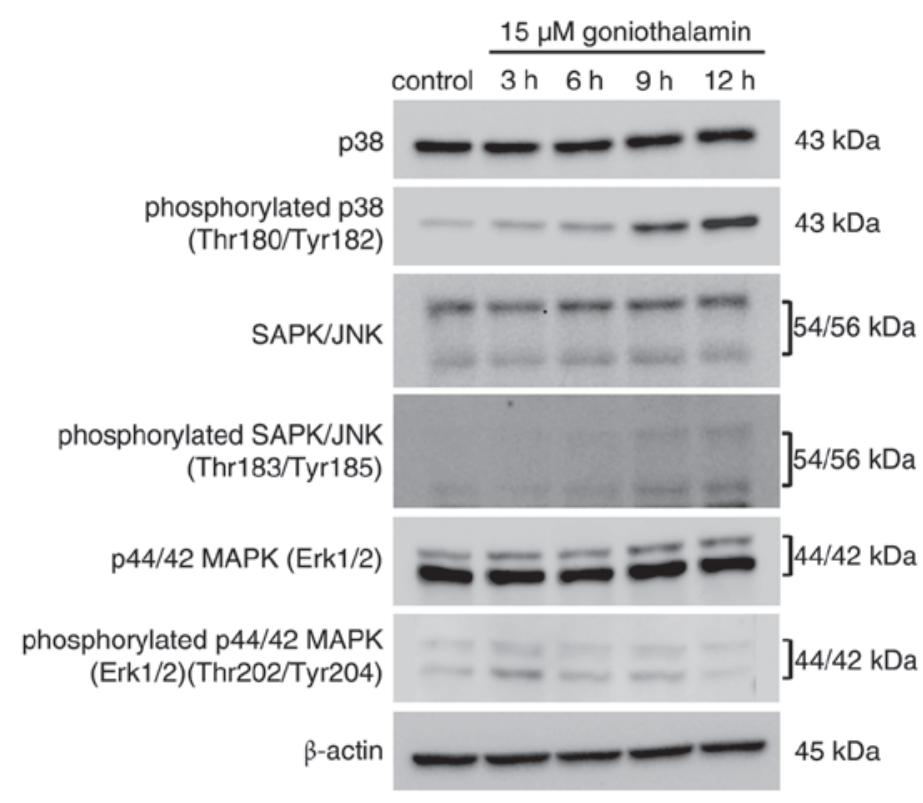

B

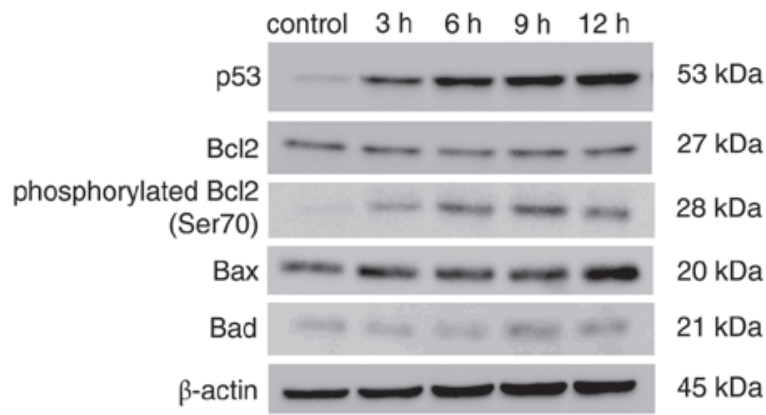

C

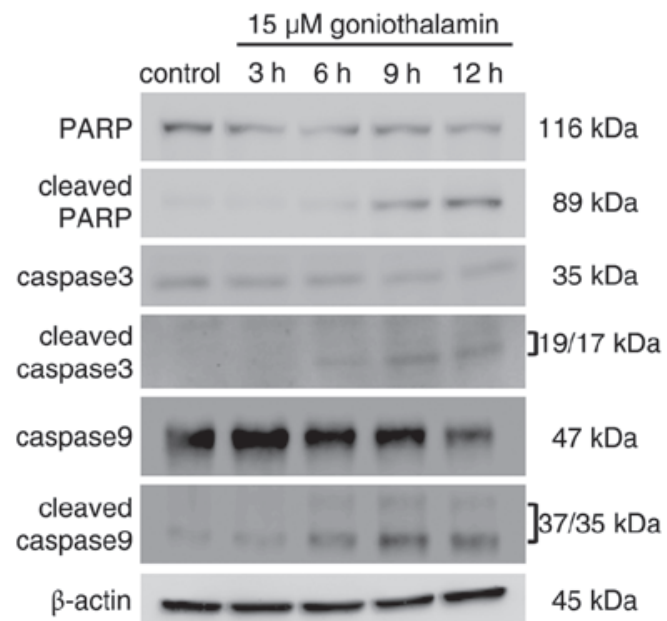

Figure 6. MAPK activation is associated with the induction of apoptosis. HeLa cells were treated with $15 \mu \mathrm{M}$ of goniothalamin for $3,6,9$ and $12 \mathrm{~h}$. Immunoblotting assays of (A) MAPK pathway mediators, (B) apoptosis mediators, and (C) p53, antiapoptotic Bcl2, proapoptotic Bax and Bad molecules and phosphorylated Bcl2 (Ser70). The results indicated that goniothalamin induced apoptosis in HeLa cells, associated with activation of the MAPK pathway. Images shown are representative from three independent experiments. MAPK, mitogen-activated protein kinase; SAPK, stress-activated protein kinase; JNK, c-Jun $\mathrm{NH}_{2}$-terminal kinase; Erk1/2. extracellular signal-regulated kinase 1/2; PARP, poly ADP ribose polymerase; Bcl2, B cell lymphoma 2; Bax, $\mathrm{Bcl} 2$-associated X protein; Bad, Bcl2-associated death promoter.

(Fig. 2B). In addition, activation of the caspase cascade was triggered and resulted in apoptotic cell death. Following the loss of mitochondrial membrane potential in the apoptotic cells, the released cytochrome $c$ interacts with Apaf-1 and forms the apoptosome, which activates caspase- 9 and then caspase-3, and destroys PARP (41-43). This results in cells undergoing apoptotic cell death. In the present study, the activation of initiator caspase- 9 and executioner caspase-3, and the inactivation of PARP were investigated The results (Fig. 6B) showed increases in the cleaved form of caspase-9, caspase-3 and PARP in the goniothalamin-treated HeLa cells in a time-dependent manner. Thus, goniothalamin may have induced apoptosis through the mitochondria-mediated pathway or intrinsic pathway in the HeLa cells. The activation of initiator caspase- 8 , which is a mediator of the death receptor-mediated pathway or extrinsic pathway, was observed in the present study; however, the active form of caspase- 8 was not detected (data not shown). In a previous report by Petsoponsakul et al (11), it was shown that goniothalamin increased the activation of caspase- 8 in human leukemic HL-60 cells, but not in human leukemic U937 cells. Thus, whether goniothalamin induced apoptosis through the intrinsic or extrinsic pathway was dependent on the specific cell type.
The present study also investigated the ER stress-associated mitochondrial-mediated apoptosis signaling pathway. Generally, the ER stress response of cells depends on its severity. The ER chaperone, GRP78, usually binds to the transmembrane ER proteins, including PERK, ATF6 and IRE1 $\alpha$, preventing their activation by dimerization or polymerization. However, when unfolded proteins accumulate in the ER, GRP78 is released from transmembrane ER proteins to target the accumulated unfolded protein, and these transmembrane ER proteins are then activated by dimerization or polymerization to initiate the UPR. In initial or mild ER stress, the UPR is triggered to recover homeostasis in ER and reestablish ER function. Prolonged or severe ER stress triggers ER stress-induced apoptosis $(12,13)$. One ER stress-associated mitochondria-mediated apoptosis signaling pathway is the cascade of IRE1 $\alpha \rightarrow$ spliced XBP1 $\rightarrow$ JNK $\rightarrow$ loss of mitochondrial membrane activation $(16,44)$. The activated IRE1 $\alpha$ has ribonuclease and kinase activities, and one signaling pathway of IRE1 $\alpha$ activation is to promote the mRNA splicing of XBP1 via its ribonuclease activity. The spliced XBP1 mRNA is translated to spliced XBP1 protein, an active transcription factor, which regulates the transcription of several UPR genes, including ER chaperones and genes encoding the components of ER-associated degradation, including 
ERdj4 (45). Another signaling pathway of IRE1 $\alpha$ activation is the activation of JNK via phosphorylation, resulting in the JNK-mediated apoptotic pathway $(46,47)$. The JNK mediator is one of the MAPK signaling molecules, which is critical in the determination of cell fate between proliferation and death. Several studies have reported that the mechanisms underlying the induction of apoptosis in cancer cells by anticancer agents are regulated through the MAPK signaling pathway $(17,18,48)$. Another ER stress-mediated apoptosis signaling pathway is the activation of PERK. Activated PERK signaling leads to the increase translation of specific mRNAs, including ATF4, which is a transcription factor for pro-apoptotic CHOP and GADD34 proteins, resulting in the initiation of apoptosis signaling (49).

To the best of our knowledge, the present study was the first to demonstrate that ER stress- and MAPK signaling-associated apoptosis were activated in goniothalamin-treated HeLa cells. The results showed that goniothalamin induced the mRNA splicing of XBP1 (Fig. 5B). The ratio of spliced:unspliced XBP1 increased following goniothalamin treatment for $12 \mathrm{~h}$. In addition, goniothalamin treatment upregulated the mRNA expression levels of ER stress-associated genes, including CHOP, ERdj4 and GADD34. However, GRP78 did not respond to goniothalamin treatment at either the mRNA or protein levels, although other evidence supported that goniothalamin treatment induced ER stress in the HeLa cells (Fig. 5A and C). These finding suggested that goniothalamin may induce ER stress in HeLa cells by a different mechanism to that observed in several other ER stress inducers, including tunicamycin, thapsigargin and brefeldin A (50). Furthermore, the present study found the MAPK pathway, was activated, particularly through JNK phosphorylation, as were associated apoptosis-associated events downstream of this activation, including the phosphorylation of $\mathrm{Bcl} 2$, triggering the loss of mitochondrial membrane potential. These results corresponded with the IRE1 $\alpha$ activation pathway (51). The results of the present study are the first, to the best of our knowledge, to show that goniothalamin triggered the ER stress-associated activation of IRE1 $\alpha$, and activated JNK through phosphorylation associated with the mitochondria-mediated induction of apoptosis.

In conclusion, although goniothalamin-induced apoptosis in the HeLa cell line has been previously reported, as mentioned above, the present study is the first, to the best of our knowledge, to show that the induction of apoptosis in the HeLa cell line by goniothalamin was associated with the ER stress-induced activation of JNK. The effect of goniothalamin on the ER stress-induced activation of JNK may be useful for further investigations of the drug action of styryl-lactone compounds, and suggests a potential candidate for preventive and therapeutic applications in the treatment of cervical cancer.

\section{Acknowledgements}

The present study was supported by The Royal Golden Jubilee Ph.D. Program (grant no. PHD/0214/2551), Thailand Research Fund, Thailand and Center of Excellence in Biological Activities of Bioactive Compounds, the Strategic Wisdom and Research Institute (grant no. 127/2558) and Srinakharinwirot University (Bangkok, Thailand).

\section{References}

1. Mereyala HB and Joe M: Cytotoxic activity of styryl lactones and their derivatives. Curr Med Chem Anticancer Agents 1: 293-300, 2001.

2. de Fátima Â, Modolo LV, Conegero LS, Pilli RA, Ferreira CV, Kohn LK and de Carvalho JE: Styryl lactones and their derivatives: Biological activities, mechanisms of action and potential leads for drug design. Curr Med Chem 13: 3371-3384, 2006.

3. Jewers K, Davis JR, Dougan J, Machanda AH, Blunden G, Kyi A and Wetchapinan S: Goniothalamin and its distribution in four goniothalamus species. Phytochemistry 11: 2025-2030, 1972.

4. Seyed MA, Jantan I and Bukhari SN: Emerging anticancer potentials of goniothalamin and its molecular mechanisms. Biomed Res Int 2014: 536508, 2014.

5. Inayat-Hussain SH, Annuar BO, Din LB, Ali AM and Ross D: Loss of mitochondrial transmembrane potential and caspase- 9 activation during apoptosis induced by the novel styryl-lactone goniothalamin in HL-60 leukemia cells. Toxicol In Vitro 17: 433-439, 2003.

6. Rajab NF, Hamid ZA, Hassan H, Ali MA, Din LB and Inayat-Hussain $\mathrm{SH}$ : Evaluation of the cytotoxic and genotoxic effects of goniothalamin in leukemic cell lines. Environ Mutagen Res 27: 161-164, 2005.

7. Wattanapiromsakul C, Wangsintaweekul B, Sangprapan P, Itharat A and Keawpradub N: Goniothalamin, a cytotoxic compound, isolated from Goniothalamus macrophyllus (Blume) Hook. f. \& Thomson var. macrophyllus. Songklanakarin Journal of Science and Technology 27: 480-487, 2005.

8. de Fátima A, Kohn LK, Antônio MA, de Carvalho E and Pilli RA (R)-Goniothalamin: Total syntheses and cytotoxic activity against cancer cell lines. Bioorg Med Chem 13: 2927-2933, 2005.

9. Alabsi AM, Ali R, Ali AM, Al-Dubai SAR, Harun H, Abu Kasim NH and Alsalahi A: Apoptosis induction, cell cycle arrest and in vitro anticancer activity of goniothalamin in a cancer cell lines. Asian Pac J Cancer Prev 13: 5131-5136, 2012.

10. Alabsi AM, Ali R, Ali AM, Harun H, Al-Dubai SA, Ganasegeran K, Alshagga MA, Salem SD and Abu Kasim NH: Induction of caspase-9, biochemical assessment and morphological changes caused by apoptosis in cancer cells treated with goniothalamin extracted from Goniothalamus macrophyllus. Asian Pac J Cancer Prev 14: 6273-6280, 2013.

11. Petsophonsakul P, Pompimon W and Banjerdpongchai R: Apoptosis induction in Human leukemic promyelocytic HL-60 and monocytic U937 cell lines by goniothalamin. Asian Pac J Cancer Prev 14: 2885-2889, 2013.

12. Xu C, Bailly-Maitre B and Reed JC: Endoplasmic reticulum stress: Cell life and death decisions. J Clin Invest 115: 2656-2664, 2005.

13. Szegezdi E, Logue SE, Gorman AM and Samali A: Mediators of endoplasmic reticulum stress-induced apoptosis. EMBO Rep 7: 880-885, 2006.

14. Elmore S: Apoptosis: A review of programmed cell death. Toxicol Pathol 35: 495-516, 2007.

15. Nikoletopoulou V, Markaki M, Palikaras K and Tavernarakis N: Crosstalk between apoptosis, necrosis and autophagy. Biochim Biophys Acta 1833: 3448-3459, 2013.

16. Win S, Than TA, Fernandez-Checa JC and Kaplowitz N: JNK interaction with Sab mediates ER stress induced inhibition of mitochondrial respiration and cell death. Cell Death Dis 5: e989, 2014.

17. Yuan L, Wang J, Xiao H, Wu W, Wang Y and Liu X: MAPK signaling pathways regulate mitochondrial-mediated apoptosis induced by isoorientin in human hepatoblastoma cancer cells. Food Chem Toxicol 53: 62-68, 2013

18. Sui X, Kong N, Ye L, Han W, Zhou J, Zhang Q, He C and Pan H: p38 and JNK MAPK pathways control the balance of apoptosis and autophagy in response to chemotherapeutic agents. Cancer Lett 344: 174-179, 2014.

19. Ferlay J, Soerjomataram I, Dikshit R, Eser S, Mathers C, Rebelo M, Parkin DM, Forman D and Bray F: Cancer incidence and mortality worldwide: Sources, methods and major patterns in GLOBOCAN 2012. Int J Cancer 136: E359-E386, 2015.

20. Siegel R, Naishadham D and Jemal A: Cancer statistics, 2013. CA Cancer J Clin 63: 11-30, 2013.

21. Saxena U, Sauvaget C and Sankaranarayanan R: Evidence-based screening, early diagnosis and treatment strategy of cervical cancer for national policy in low- resource countries: Example of India. Asian Pac J Cancer Prev 13: 1699-1703, 2012. 
22. Landry JJ, Pyl PT, Rausch T,Zichner T, Tekkedil MM, Stütz AM, Jauch A, Aiyar RS, Pau G, Delhomme N, et al: The genomic and transcriptomic landscape of a HeLa cell line. G3 (Bethesda) 3: 1213-1224, 2013

23. Denizot F and Lang R: Rapid colorimetric assay for cell growth and survival: Modifications to the tetrazolium dye procedure giving improved sensitivity and reliability. J Immunol Methods 89: 271-277, 1986.

24. Oberhammer FA, Hochegger K, Fröschl G, Tiefenbacher R and Pavelka M: Chromatin condensation during apoptosis is accompanied by degradation of Lamin $\mathrm{A}+\mathrm{B}$, without enhanced activation of cdc2 kinase. J Cell Biol 126: 827-837, 1994.

25. Krishan A: Rapid flow cytofluorometric analysis of mammalian cell cycle by propidium iodide staining. J Cell Biol 66: 188-193, 1975.

26. Perelman A, Wachtel C, Cohen M, Haupt S, Shapiro H and Tzur A: JC-1: Alternative excitation wavelengths facilitate mitochondrial membrane potential cytometry. Cell Death Dis 22: e430, 2012

27. Livak KJ and Schmittgen TD: Analysis of relative gene expression data using real-time quantitative PCR and the 2- $\Delta \Delta C T$ method. Methods 25: 402-408, 2001.

28. Taylor SC and Posch A: The design of a quantitative western blot experiment. Biomed Res Int 2014: 361590, 2014

29. Bradford MM: A rapid and sensitive method for the quantitation of microgram quantities of protein utilizing the principle of protein-dye binding. Anal Biochem 72: 248-254, 1976.

30. Shankar S, Kumar D and Srivastava RK: Epigenetic modifications by dietary phytochemicals: Implications for personalized nutrition. Pharmacol Ther 138: 1-17, 2013.

31. Yen CY, Chiu CC, Haung RW, Yeh CC, Huang KJ, Chang KF, Hseu YC, Chang FR, Chang HW and Wu YC: Antiproliferative effects of goniothalamin on Ca9-22 oral cancer cells through apoptosis, DNA damage and ROS induction. Mutat Res 747: 253-258, 2012

32. Chen WY, Wu CC, Lan YH, Chang FR, Teng CM and Wu YC: Goniothalamin induces cell cycle-specific apoptosis by modulating the redox status in MDA-MB-231 cells. Eur J Pharmacol 522: 20-29, 2005

33. Thornton TM and Rincon M: Non-classical p38 map kinase functions: Cell cycle checkpoints and survival. Int J Biol Sci 5: 44-51, 2009.

34. Fadok VA, Bratton DL, Frasch SC, Warner ML and Henson PM: The role of phosphatidylserine in recognition of apoptotic cells by phagocytes. Cell Death Diff 5: 551-562, 1998.

35. Denecker G, Dooms H, Van Loo G, Vercammen D, Grooten J, Fiers W, Declercq W and Vandenabeele P: Phosphatidyl serine exposure during apoptosis precedes release of cytochrome c and decrease in mitochondrial transmembrane potential. FEBS Lett 465: 47-52, 2000

36. Rello S, Stockert JC, Moreno V, Gámez A, Pacheco M, Juarranz A, Cañete M and Villanueva A: Morphological criteria to distinguish cell death induced by apoptotic and necrotic treatments. Apoptosis 10: 201-208, 2005.
37. Hanshaw RG and Smith BD: New reagents for phosphatidylserine recognition and detection of apoptosis. Bioorg Med Chem 13: 5035-5042, 2005.

38. Al-Qubaisi M, Rosli R, Subramani T, Omar AR, Yeap SK, Ali AM and Alitheen NB: Goniothalamin selectively induces apoptosis on human hepatoblastoma cells through caspase-3 activation. Nat Prod Res 27: 2216-2218, 2013.

39. Luo X, Budihardio I, Zou H, Slaughter C and Wang X: Bid, a $\mathrm{Bcl}-2$ interacting protein, mediates cytochrome c release from mitochondria in response to activation of cell surface death receptors. Cell 94: 481-490, 1998.

40. Yen HK, Fauzi AR, Din LB, McKelvey-Martin VJ, Meng CK, Inayat-Hussain SH and Rajab NF: Involvement of Seladin-1 in goniothalamin-induced apoptosis in urinary bladder cancer cells BMC Complement Altern Med 14: 295, 2014.

41. Boatright KM and Salvesen GS: Mechanisms of caspase activation. Curr Opin Cell Biol 15: 725-731, 2003.

42. Riedl SJ and Shi Y: Molecular mechanisms of caspase regulation during apoptosis. Nat Rev Mol Cell Biol 5: 897-907, 2004.

43. Pop C, Timmer J, Sperandio S and Salvesen GS: The apoptosome activates caspase-9 by dimerization. Mol Cell 22: 269-275, 2006.

44. Lee H, Park M, Choi B, Oh E, Song M, Lee J, Kim C, Lim BU and Park HJ: Endoplasmic reticulum stress-induced JNK activation is a critical event leading to mitochondria-mediated cell death caused by $\beta$-lapachone treatment. PLoS One 6: e21533, 2011.

45. Chen Y and Brandizzi F: IRE1: ER stress sensor and cell fate executor. Trends Cell Biol 23: 547-555, 2013.

46. Selimovic D, Ahmad M, El-Khattouti A, Hannig M, Haïkel Y and Hassan M: Apoptosis-related protein-2 triggers melanoma cell death by a mechanism including both endoplasmic reticulum stress and mitochondrial dysregulation. Carcinogenesis 32: 1268-1278, 2011.

47. Urano F, Wang X, Bertolotti A, Zhang Y, Chung P, Harding HP and Ron D: Coupling of stress in the ER to activation of JNK protein kinases by transmembrane protein kinase IRE1. Science 287: 664-666, 2000

48. Wada T and Penninger JM: Mitogen-activated protein kinases in apoptosis regulation. Oncogene 23: 2838-2849, 2004.

49. Novoa I, Zeng H, Harding HP and Ron D: Feedback inhibition of the unfolded protein response by GADD34-mediated dephosphorylation of eIF2alpha. J Cell Biol 153: 1011-1022, 2001.

50. Shinjo S, Mizotani Y, Tashiro E and Imoto M: Comparative analysis of the expression patterns of UPR-target genes caused by UPR-inducing compounds. Biosci Biotechnol Biochem 77: 729-735, 2013.

51. Annis MG, Yethon JA, Leber B and Andrews DW: There is more to life and death than mitochondria: $\mathrm{Bcl}-2$ proteins at the endoplasmic reticulum. Biochim Biophys Acta 1644: 115-123, 2004. 